\title{
Probable immersions for novel Coronavirus and its preventions:
}

\section{A systematic review}

\author{
Parth M. Kapatel ${ }^{1 *}$, Nagma ara Malik ${ }^{2}$
}

\section{ABSTRACT}

The new public health crisis threatening the world with the emergence due to the spreading of 2019 novel coronavirus (2019-nCoV) or it can also say as severe acute respiratory syndrome coronavirus 2 (SARS-CoV-2). The virus instigated in bats and was transmitted to humans through yet unknown transitional animals in Wuhan, Hubei province, China in December 2019. There have been around 3.04 million reported cases by WHO of coronavirus disease 2019 (COVID-2019) and 895 thousand are recovered, 211 thousand reported deaths to date (28/04/2020) from all over the world. The disease is spread by inhalation/breathing or interaction with infected droplets. The quarantine period ranges from 2 to 14 days. The symptoms are typically breathlessness, cough, sore throat, fever, fatigue, malaise, among others. The disease is mild in most people; while in about some (generally the aged and those with comorbidities), it may progress to pneumonia, acute respiratory distress syndrome (ARDS) and multi-organ dysfunction. Many people are asymptomatic. Treatment is very essentially supportive; the role of antiviral agents is up till now to be recognized. Prevention requires home quarantine of alleged cases and those with mild illnesses and severe infection control measures at hospitals that contain interaction, touch and droplet precautions.

\section{Keywords: Corona, SARS-CoV-2, COVIDE19, quarantine, Isolation}

Coronaviruses are an assembly of related infections/viruses that cause sicknesses in wellevolved creatures and winged animals. In people, coronaviruses cause respiratory tract diseases that can extend from gentle to deadly. Mellow ailments integrate a few instances of the normal cold (which is caused additionally by certain different infections, prevalently rhinoviruses), while increasingly deadly assortments can cause SARS, MERS, and COVID19. Side effects in different species change: in chickens, they cause an upper respiratory tract sickness, while in cows and pigs, they cause diarrhea. There are up 'til now no antibodies or antiviral medications to forestall or treat human coronavirus contaminations [1-4].

Coronaviruses comprise the subfamily Orthocoronavirinae, in the family Coronaviridae, request Nidovirales, and domain Riboviria [5]. They are encompassed viruses with a positivesense single-abandoned RNA genome and a nucleocapsid of helical evenness. The genome

\footnotetext{
${ }^{1}$ Department of Materials Science, Sardar Patel University, Vallabh Vidyanagar, 388120, Gujarat, India

${ }^{2}$ J \& J college of science, Microbiology, Sardar Patel University, Nadiad, 387001, Gujarat, India

*Responding Author

Received: April 14, 2020; Revision Received: May 03, 2020; Accepted: May 25, 2020
}

(C) 2020, Kapatel. P.M., Nagma. M; licensee IJIP. This is an Open Access Research distributed under the terms of the Creative Commons Attribution License (www.creativecommons.org/licenses/by/2.0), which permits unrestricted use, distribution, and reproduction in any Medium, provided the original work is properly cited. 
size of coronaviruses varieties from roughly 27 to 34 kilobases, the biggest among known RNA viruses. The name coronavirus is gotten from the Latin corona, signifying "crown" or "radiance(halo)", which alludes to the trademark appearance suggestive of a crown or a sun oriented corona around the virions (infection particles) when seen under two-dimensional transmission electron microscopy [6]. Figure 1 shows the surface of the virus being shrouded in club-shaped protein spikes. Coronaviruses are large pleomorphic circular particles with bulbous surface projections. The width of the virus particles is around $120 \mathrm{~nm}$. The envelope of the virus in electron micrographs shows up as a particular pair of electron thick shells [7].

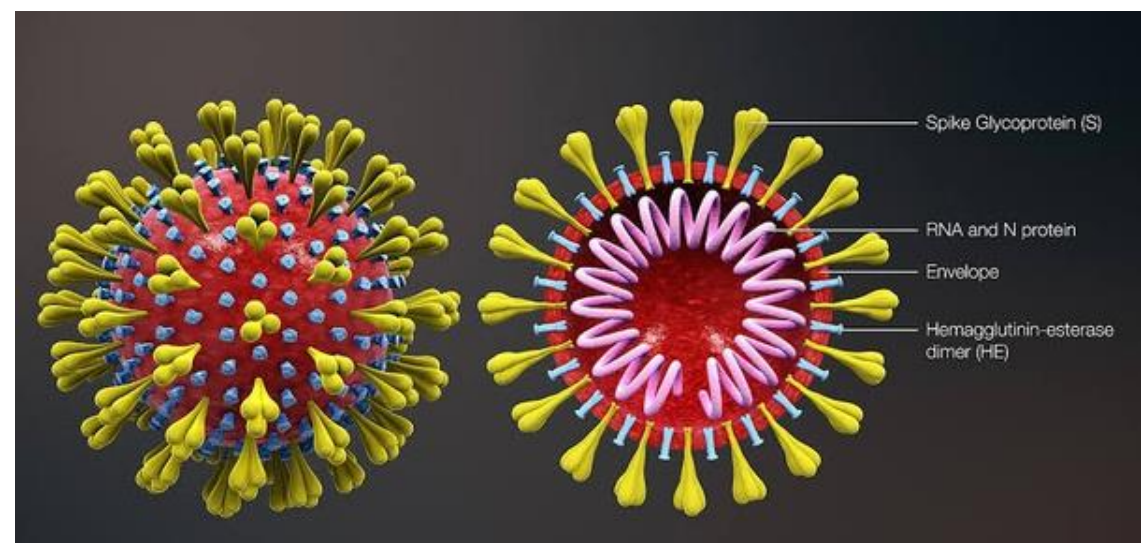

Figure 1. Club-shaped protein spikes

Coronavirus virions are round to pleomorphic encompassed particles. The envelope is studded with anticipating glycoproteins and encompasses a center comprising of matrix protein encased inside, which is a solitary strand of positive-sense RNA related to nucleoprotein. The envelope glycoproteins are liable for connection to the host cell and furthermore convey the fundamental antigenic epitopes, especially the epitopes perceived by neutralizing/killing antibodies [8,9]. The cross-section of the corona virus appears in Figure 2.

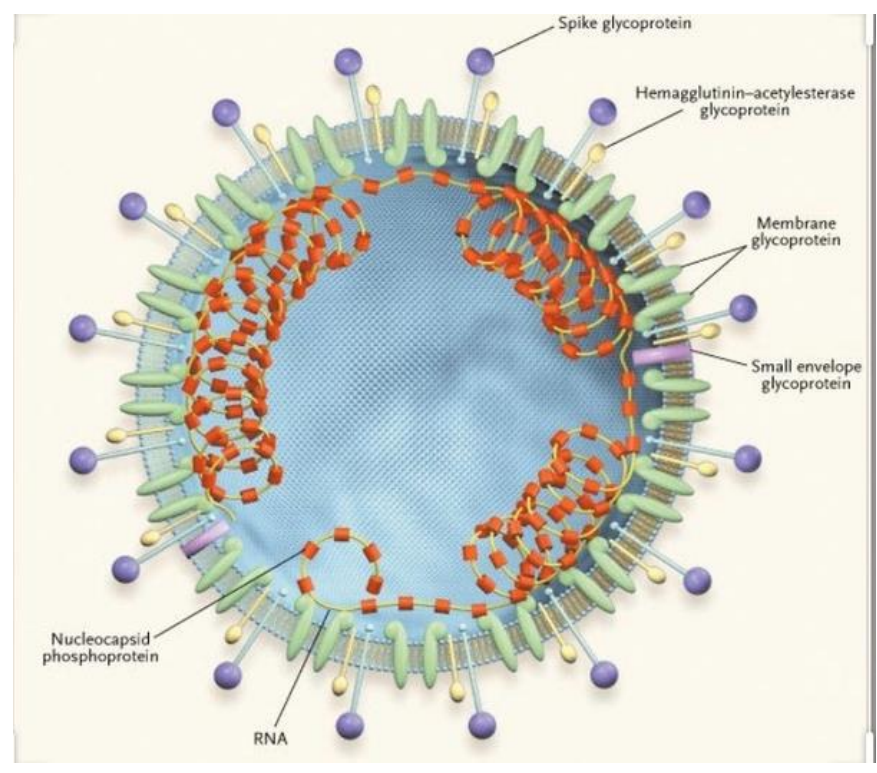

Figure 2. The cross-section view of coronavirus 


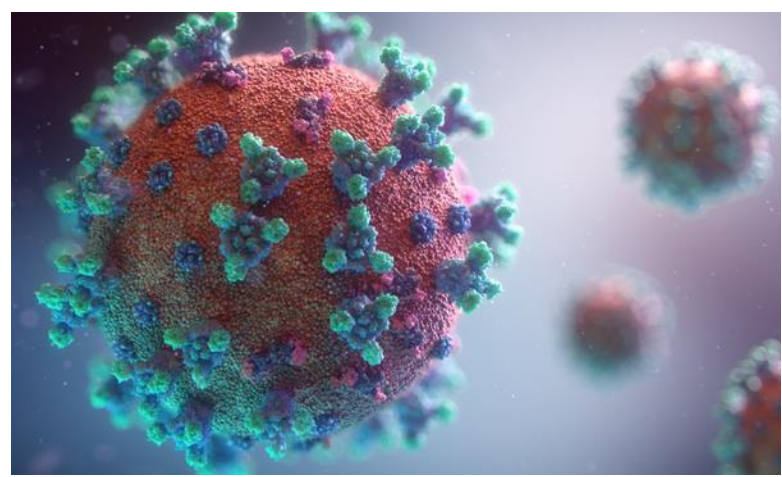

Figure 3. 3D model of coronavirus

A 3D model of the surface of the coronavirus COVID-19 has been released, to aid researchers in the development of a treatment shown in Figure 3. It was created by Fusion Animation; this new model is available for free for scientists to use in the development of treatments to combat the condition. The model was created by assembling 3D parts together from related COVID-19 coronavirus structures available in public databases [10]. The components used by the developers includes:

- $\quad$ Spike (S) protein (PDB code - 6CRV)

- Envelope (E) protein (PDB code - 5X29)

- Membrane (M) protein (PDB code - 3I6G)

They note that the $\mathrm{M}$ protein shown is complexed with HLA-A *02 (human leukocyte antigen serotype).

The circulation of these proteins on the outside of the infection was adjusted by an irregular algorithm. The general portrayal of surface protein density has been decreased to help show $\mathrm{S}, \mathrm{E}$ and $\mathrm{M}$ proteins. The $\mathrm{M}$ lipid itself was created utilizing a molecule framework to deliver an arbitrary and organic outcome.

The models were cross-referenced with data from Korkinlab, the US Centers for Disease Control and Prevention (CDC) and the Worcester Polytechnic Institute (WPI), US. The researchers at WPI utilized an as of late published viral genome of the coronavirus made accessible at the National Center for Biotechnology Information. They, at that point, used sub-atomic displaying to reproduce the 3D structure of major viral proteins and their relationships with human proteins. Their COVID-19 auxiliary genomics map is accessible to scientists and anybody in the overall globe.

"We're confident that our data and visual models could provide the guidance for experimental scientists worldwide who are working feverishly to solve this pandemic," said Professor Dmitry Korkin, director of the WPI's bioinformatics and computational biology program.

As indicated by the inventors, the inward structures of the COVID-19 infection/virus are right now being explored and incorporated into another perception. Like in to say that, in people, coronaviruses are RNA viruses that cause respiratory tract contaminations which can be mellow, for example, a few instances of the basic cold and others that can be deadly, for example, SARS, MERS, and COVID-19 [11]. 
The 2019 novel coronavirus (2019-nCoV) or the extreme intense respiratory disorder crown infection 2 (SARS-CoV-2) as it is presently called, is quickly spreading from its source in Wuhan City of Hubei Province of China to the remainder of the world [12]. Till 28/04/2020, around 3.04 million revealed cases of coronavirus ailment 2019 (COVID-2019) and 895 thousand are recouped, 211 thousand announced dead. India has declared 29,435 cases till date. Luckily, up until now, youngsters have been rarely influenced by fewer deaths. In any case, the future course of this infection is obscure. This article gives an elevated view of this new infection. Since information about this infection is quickly developing, readers are encouraged to update themselves on a regular basis [13].

\section{Mode of action}

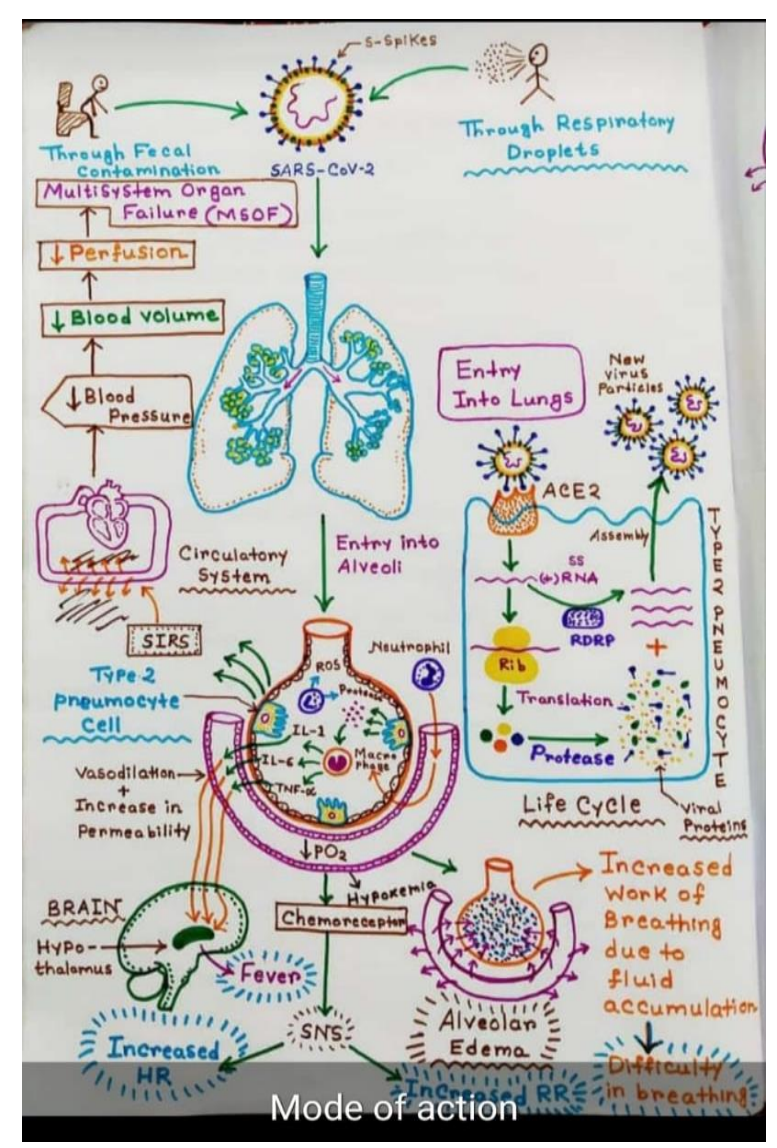

Figure 4. The Mode of action

\section{REPLICATION CYCLE}

\section{Entry}

Contamination starts when the viral spike (S) glycoprotein joins to its correlative host cell receptor. After connection, a protease of the host cell separates and enacts the receptor-joined spike protein. Contingent upon the host cell protease accessible, cleavage and activation permits the virus to enter the host cell by endocytosis or direct combination of the viral wrap with the host membrane. On access into the host cell, the virus molecule is uncoated, and its genome enters the cell cytoplasm. The coronavirus RNA genome has a 5' methylated cap and a 3' polyadenylated tail, which permits the RNA to join to the host cell's ribosome for translation. The host ribosome interprets the underlying covering open perusing casing of the virus genome and structures a long polyprotein. The polyprotein has its own proteases which divide the polyprotein into different non-structural proteins [14]. 


\section{REPLICATION}

Some of the non-structural proteins mix to produce a multi-protein replicase-transcriptase complex (RTC). The principle replicase-transcriptase protein is the RNA-subordinate RNA polymerase (RdRp). It is legitimately associated with the replication and translation of RNA from an RNA strand. The other non-structural proteins in the unpredictable aid the replication and transcription process. The exoribonuclease non-structural protein, for example, gives additional constancy to replication by giving an editing capacity which the RNA-subordinate RNA polymerase lacks. One of the principal elements of the complex is to imitate the viral genome. RdRp legitimately intervenes in the blend of negative-sense genomic RNA from the positive-sense genomic RNA. This is trailed by the replication of positive-sense genomic RNA from the negative-sense genomic RNA. The other significant function of the complex is to decipher the viral genome. RdRp straightforwardly intervenes in the synthesis of negativesense subgenomic RNA molecules from the positive-sense genomic RNA. This is trailed by the translation of these negative-sense subgenomic RNA atoms to their relating positivesense mRNAs.

\section{RELEASE}

The duplicated positive-sense genomic RNA turns into the genome of the offspring infections. The mRNAs are gene transcripts of the last third of the virus genome after the early covering reading frame. These mRNAs are translated by the host's ribosomes into the basic proteins and various adornment proteins. RNA interpretation happens inside the endoplasmic reticulum. The viral structural proteins $\mathrm{S}, \mathrm{E}$, and $\mathrm{M}$ move along the secretory pathway into the Golgi transitional compartment. There, the M proteins direct most proteinprotein interactions required for the get together of the virus following its binding to the nucleocapsid. Progeny viruses are then discharged from the host cell by exocytosis through secretory vesicles.

\section{TRANSMISSION}

The interaction of the coronavirus spike protein with its complement host cell receptor is central in determining the tissue tropism, infectivity, and species range of the virus. The SARS coronavirus, for example, infects human cells by attaching to the angiotensinconverting enzyme 2 (ACE2) receptor.

The communication of the coronavirus spike protein with its supplement host cell receptor is central in deciding the tissue tropism, infectivity, and species scope of the virus. The SARS coronavirus, for instance, taints human cells by appending to the angiotensin-changing over enzyme 2 (ACE2) receptor. Four coronaviruses, namely HKU1, NL63, 229E and OC43 have been in circulation in humans and generally cause mild respiratory disease.

\section{CLASSIFICATION}

For a more detailed list of members, see Coronaviridae. 


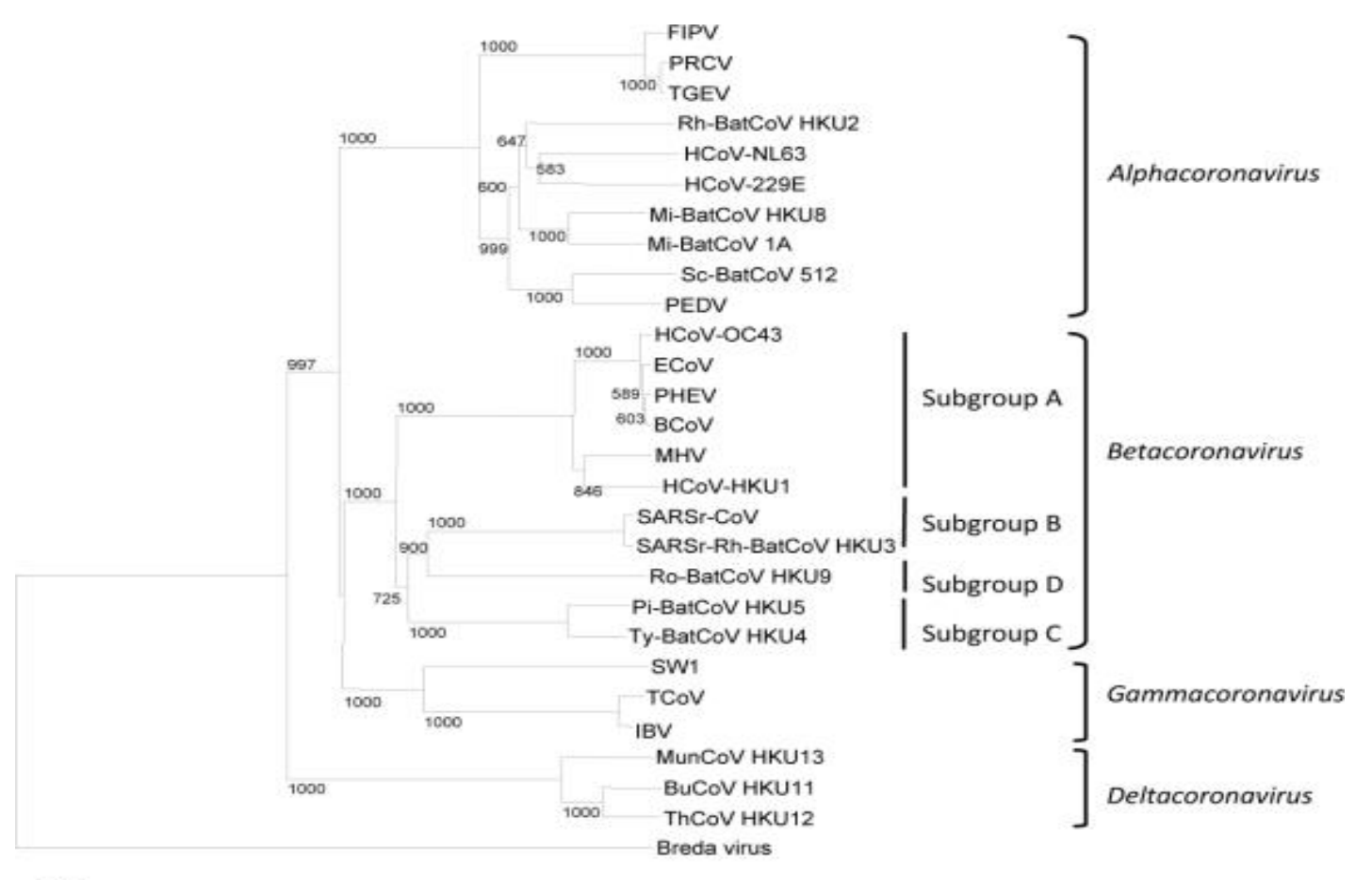

\section{PHYLOGENETIC TREE OF CORONA VIRUSES}

The scientific name for coronavirus is Orthocoronavirinae or Coronavirinae.[2][3][4] Coronaviruses belong to the family of Coronaviridae, order Nidovirales, and realm Riboviria.[5][6] They are divided into alphacoronaviruses and betacoronaviruses which infect mammals - and gammacoronaviruses and deltacoronaviruses which primarily infect birds. Genus: Alphacoronavirus; type species: Alphacoronavirus 1 (TGEV) Species: Alphacoronavirus 1, Human coronavirus 229E, Human coronavirus NL63, Miniopterus bat coronavirus 1, Miniopterus bat coronavirus HKU8, Porcine epidemic diarrhea virus, Rhinolophus bat coronavirus HKU2, Scotophilus bat coronavirus 512 Genus Betacoronavirus; type species: Murine coronavirus (MHV) Species: Betacoronavirus 1 (Bovine Coronavirus, Human coronavirus OC43), Hedgehog coronavirus 1, Human coronavirus HKU1, Middle East respiratory syndrome-related coronavirus, Murine coronavirus, Pipistrellus bat coronavirus HKU5, Rousettus bat coronavirus HKU9, Severe acute respiratory syndrome-related coronavirus (SARS-CoV, SARS-CoV-2), Tylonycteris bat coronavirus HKU4 Genus Gammacoronavirus;[15] type species: Avian coronavirus (IBV) Species: Avian coronavirus, Beluga whale coronavirus SW1 Genus Deltacoronavirus; type species: Bulbul coronavirus HKU11 Species: Bulbul coronavirus HKU11, Porcine coronavirus HKU15

\section{EPIDEMIOLOGY AND PATHOGENESIS}

All ages are defenceless. Contamination is transmitted through huge beads produced during coughing and sneezing by symptomatic patients yet can likewise happen from asymptomatic individuals and before the beginning of side effects [15]. Studies have demonstrated higher viral loads in the nasal pit when contrasted with the throat with no distinction in viral burden among symptomatic and asymptomatic individuals [16]. Patients can be irresistible for whatever length of time that the manifestations keep going and even on clinical recuperation. A few people may go about as super spreaders; a UK resident who went to a meeting in Singapore contaminated 11 others while remaining in a retreat in the French Alps and upon coming back to the UK. These contaminated beads/droplets can spread 1-2 meters and store 
on surfaces. The virus can stay feasible on surfaces for quite a long time in good air conditions however, they are pulverized in under a moment by basic disinfectants like sodium hypochlorite, hydrogen peroxide and so forth [17]. The disease is procured either by the inward breath of these droplets or contacting surfaces spoiled by them and afterward contacting the nose, mouth and eyes. The infection is additionally present in the stool and pollution of the water flexibly and resulting transmission by means of aerosolization/feco oral course is likewise hypothesized. According to current data, transplacental transmission from pregnant ladies to their embryo has not been observed [18]. However, neonatal ailment because of post-natal transmission is observed [18]. The brooding time frame changes from 2 to 14 days [median 5 days]. Studies have recognized angiotensin receptor 2 (ACE2) as the receptor through which the virus enters the respiratory mucosa [15]. The essential case generation rate (BCR) is evaluated to run from 2 to 6.47 in different demonstrating examines. In correlation, the BCR of SARS was 2 and 1.3 for pandemic influenza H1N1 2009.

\section{CLINICAL FEATURES}

The clinical highlights of COVID-19 are differed, running from asymptomatic state to intense respiratory pain disorder and multi-organ dysfunction. The regular clinical highlights incorporate sore throat, fever (not on the whole), cough, cerebral pain, exhaustion, migraine, myalgia and shortness of breath. Conjunctivitis has likewise been represented. Along these lines, they are indistinct from other respiratory contaminations. In a subset of patients, before the finish of the first week, the infection can advance to pneumonia, respiratory failure and deaths. This movement is related to outrageous ascent in provocative cytokines, including IL2, IL7, IL10, GCSF, IP10, MCP1, MIP1A, and TNF $\alpha$ [19]. The middle time from the beginning of side effects to dyspnea was 5-day, hospitalization 7 day and intense respiratory trouble disorder (ARDS) 8 days. The requirement for serious consideration affirmation was in 25-30\% of influenced patients in published series. Intricacies saw included intense lung injury, ARDS, stun and intense kidney injury. Recuperation began in the second or third week.

The middle span of emergency clinic remains in the individuals who recuperated was 10 days. Antagonistic results and deaths are progressively regular in the older and those with fundamental co-morbidities (50-75\% of deadly cases). The casualty rate in hospitalized grown-up patients ran from 4 to $11 \%$. The general case casualty rate is assessed to run somewhere in the range of 2 and 3\%. Curiously, sickness in patients outside the Hubei region has been accounted for to be milder than those from Wuhan [20]. So also, the seriousness and case casualty rate in patients outside China has been accounted for to be milder. This may either be because of determination inclination wherein the cases announcing from Wuhan included just the serious cases or because of inclination of the Asian populace to the virus because of higher expression of ACE2 receptors on the respiratory mucosa [15]. Illness in neonates, new-born children and kids have been reported to be significantly milder than their adult counterparts. In a progression of 34 youngsters admitted to a medical clinic in Shenzhen, China, between January nineteenth and February seventh, there were 14 guys and 20 females. The middle age was 8 years 11 months and in 28 youngsters, the contamination was connected to a relative and 26 kids had a history of movement/habitation to Hubei territory in China. All the patients were either asymptomatic (9\%) or had gentle sickness. No severe or critical cases were seen. The most widely recognized indications were fever (half) and cough (38\%). All patients recouped with symptomatic treatment and there were no deaths. One instance of severe pneumonia and multiorgan dysfunction in a child has also been reported [21]. Additionally, Similarly, the neonatal cases that have been reported have been mild [22]. 
TREATMENT

Treatment is basically strong and symptomatic. The initial step is to guarantee satisfactory disconnection to forestall transmission to different contacts, patients and human services laborers. Gentle disease ought to be overseen at home with guiding about peril signs. The standard principles are keeping up hydration and nourishment and controlling fever and cough. Routine utilization of anti-microbials and antivirals, for example, oseltamivir ought to be maintained a strategic distance from in affirmed cases. In hypoxic patients, the arrangement of oxygen through nasal prongs, face mask, high stream nasal cannula (HFNC) or non-intrusive ventilation is indicated. Mechanical ventilation and even extra-human corporeal membrane oxygen support might be required. Renal substitution treatment might be required in a few. Anti-infection agents and antifungals are required if co-diseases are suspected. The job of corticosteroids is dubious; while current global accord and WHO advocate against their utilization, Chinese rules do prescribe momentary treatment with lowto-direct portion corticosteroids in COVID-19 ARDS. Point by point rules for basic consideration, the board for COVID-19 has been distributed by the WHO. There is, starting at now, no endorsed treatment for COVID-19. Antiviral medications, for example, ribavirin, lopinavir-ritonavir have been utilized dependent on the involvement in SARS and MERS. In a verifiable control concentrate in patients with SARS, patients treated with lopinavirritonavir with ribavirin would be wise to results when contrasted with that given ribavirin alone [18]. For the situation arrangement of 99 hospitalized patients with COVID19 contamination from Wuhan, oxygen was given to $76 \%$, noninvasive ventilation in $13 \%$, mechanical ventilation in 4\%, extracorporeal film oxygenation (ECMO) in 3\%, nonstop renal substitution treatment (CRRT) in 9\%, anti-infection agents in $71 \%$, antifungals in $15 \%$, glucocorticoids in $19 \%$ and intravenous immunoglobulin treatment in $27 \%$ [19]. Antiviral treatment comprising of oseltamivir, ganciclovir and lopinavir-ritonavir was given to $75 \%$ of the patients. The span of non-intrusive ventilation was 4-22 days [median 9 days] and mechanical ventilation for 3-20 days [median 17 days]. For the situation arrangement of youngsters talked about before, all kids recuperated with fundamental treatment and didn't require serious consideration. There is episodic involvement in the utilization of remdeswir, a wide range hostile to RNA sedate produced for Ebola in the executives of COVID-19 [23]. More proof is required before these medications are suggested. Different medications proposed for treatment are arbidol (an antiviral medication accessible in Russia and China), intravenous immunoglobulin, interferons, chloroquine and plasma of patients recuperated from COVID-19. Moreover, suggestions about utilizing customary Chinese herbs discover place in the Chinese rules.

\section{PREVENTION}

Since, as of now, there are no endorsed medications for this virus, anticipation is significant. A few properties of this infection make counteraction troublesome to be specific, nonspecific features of the disease, the infectivity even before the onset of symptoms in the incubation period, transmission from asymptomatic people, long incubation period, tropism for mucosal surfaces such as the conjunctiva, prolonged duration of the illness and transmission even after clinical recovery. Separation of affirmed or suspected cases with gentle sickness at home is suggested. The ventilation at home ought to be acceptable with daylight to take into account the pulverization of infection. Patients ought to be approached to wear simple surgical masks and practice cough hygiene. Parental figures ought to be approached to wear a careful mask when in a similar room as the patient and use hand cleanliness each 15-20 min. The most serious hazard in COVID-19 is transmission to medicinal services laborers. In the SARS outbreak of 2002, $21 \%$ of those influenced were healthcare workers [24]. The doctor who first warned about the virus has died too. It is 
important to protect healthcare workers to ensure continuity of care and to prevent transmission of infection to other patients. While COVID-19 transmits as droplets and is put in Category B of irresistible operators (exceptionally pathogenic H5N1 and SARS), by the China National Health Commission, contamination control measures suggested are those for class A specialists (cholera, plague). Patients ought to be put in discrete rooms or cohorted together. Negative weight rooms are not commonly required. The rooms and surfaces and gear ought to experience standard purification ideally with sodium hypochlorite. Human services laborers ought to be given fit tried N95 respirators and defensive suits and goggles. Airborne transmission precautionary measures ought to be taken during vaporized producing methodology, for example, intubation, attractions and tracheostomies. All contacts, including healthcare workers, should be monitored for the development of symptoms of COVID-19. Patients can be discharged from isolation once they are afebrile for at least 3 days and have two consecutive negative molecular tests at 1-day sampling interval. Negative molecular tests were not a prerequisite for discharge. At the community level, people should be asked to avoid crowded areas and postpone non-essential travel to places with ongoing transmission. They should be asked to practice cough hygiene by coughing in sleeve/ tissue rather than hands and practice hand hygiene frequently every 15-20 min. Patients with respiratory symptoms should be asked to use surgical masks. The use of a mask by healthy people in public places has not shown to protect against respiratory viral infections and is currently not recommended by WHO. A candidate vaccine is under development.

\section{PRACTICE POINTS FROM AN INDIAN PERSPECTIVE}

At the time of composing this article, the danger of coronavirus in India is nearly low because of the extended lockdown given by the government of India. Yet, that may change in the few barely any weeks. Subsequently, coming up next is suggested:

$>$ Healthcare providers should take travel history of all patients with respiratory indications, and any global travel in the previous fourteen days just as contact with sick people who have travelled internationally.

$>$ They should set up a system of triage of patients with respiratory illness in the outpatient department and give them a simple surgical mask to wear. They should use surgical masks themselves while examining such patients and practice hand hygiene frequently.

$>$ Suspected cases should be referred to government-designated centers for isolation and testing.

$>$ Patients admitted with severe pneumonia and acute respiratory distress syndrome should be evaluated for travel history and placed under contact and droplet isolation.

$>$ Regular decontamination of surfaces should be done.

$>$ They should be tested for etiology using multiplex PCR panels if logistics permit and if no pathogen is identified, refer the samples for testing for SARS-CoV-2.

$>$ All clinicians should keep themselves updated about recent developments, including the global spread of the disease. Non-essential international travel should be avoided at this time.

$>$ People should stop spreading myths and false information about the disease and try to decrease the panic and anxiety of the public.

\section{CONCLUSIONS}

This new virus outbreak has challenged the economic, medical and public health infrastructure of China and to some extent, of other countries especially, its neighbours. Time alone will tell how the virus will impact our lives here in India. More so, future outbreaks of 
viruses and pathogens of zoonotic origin are likely to continue. Therefore, apart from curbing this outbreak, efforts should be made to devise comprehensive measures to prevent future outbreaks of zoonotic origin. People should stop spreading myths and false information about the disease and try to allay panic and anxiety of the public. Stay home and be safe. Because the breaking of the chain is essential. Thus, in these days, it is only possible through staying at home. Be hygienic, wash your hands frequently. Do not touch your nose, eyes, face without washing hands. Keep sanitize the home with sanitizer and don't forget to wear a mask over the face.

\section{REFERENCES}

[1] Macnaughton, M. R., \& Davies, H. A. (1981). Human enteric coronaviruses. Archives of virology, 70(4), 301-313.

[2] Zumla, A., Chan, J. F., Azhar, E. I., Hui, D. S., \& Yuen, K. Y. (2016). Coronaviruses-drug discovery and therapeutic options. Nature reviews Drug discovery, 15(5), 327.

[3] McIntosh, K., \& Perlman, S. (2015). Coronaviruses, including severe acute respiratory syndrome (SARS) and Middle East respiratory syndrome (MERS). Mandell, Douglas, and Bennett's Principles and Practice of Infectious Diseases, Updated Edition. 8th ed. Philadelphia, PA: Elsevier Saunders.

[4] Gorbalenya, A. E. (2020). Severe acute respiratory syndrome-related coronavirus-The species and its viruses, a statement of the Coronavirus Study Group. BioRxiv.

[5] Fehr, A. R., \& Perlman, S. (2015). Coronaviruses: an overview of their replication and pathogenesis. In Coronaviruses (pp. 1-23). Humana Press, New York, NY.

[6] Davies, H. A., \& Macnaughton, M. R. (1979). Comparison of the morphology of three coronaviruses. Archives of virology, 59(1-2), 25-33.

[7] Lanser, J. A. (1979). The protein composition of infectious bronchitis virus (Doctoral dissertation, London School of Hygiene \& Tropical Medicine).

[8] Herold, J. (2005). U.S. Patent Application No. 10/839,729.

[9] Zhang, X. M., Herbst, W., Kousoulas, K. G., \& Storz, J. (1994). Biological and genetic characterization of a hemagglutinating coronavirus isolated from a diarrhoeic child. Journal of medical virology, 44(2), 152-161.

[10] Judge, A. (2020). Reimagining Coronavirus in 3D as a Metaphor of Global Society in Distress.

[11] Manandhar, S., Nakarmi, P., \& Baniya, N. A Novel Coronavirus Emerging in World-Key Questions for Developing Countries and Under Developed Countries.

[12] Wang, C., Horby, P. W., Hayden, F. G., \& Gao, G. F. (2020). A novel coronavirus outbreak of global health concern. The Lancet, 395(10223), 470-473.

[13] Coronavirus Outbreak. Available at: https://www.worldometers. info/coronavirus/. Accessed 28/04/2020.

[14] Pomerantz, R. J. (2002). Reservoirs of human immunodeficiency virus type 1: the main obstacles to viral eradication. Clinical infectious diseases, 34(1), 91-97.

[15] Bastola, A., Sah, R., Rodriguez-Morales, A. J., Lal, B. K., Jha, R., Ojha, H. C., ... \& Morita, K. (2020). The first 2019 novel coronavirus case in Nepal. The Lancet Infectious Diseases, 20(3), 279-280.

[16] Zou, L., Ruan, F., Huang, M., Liang, L., Huang, H., Hong, Z., ... \& Guo, Q. (2020). SARS-CoV-2 viral load in upper respiratory specimens of infected patients. New England Journal of Medicine, 382(12), 1177-1179.

[17] Kampf, G., Todt, D., Pfaender, S., \& Steinmann, E. (2020). Persistence of coronaviruses on inanimate surfaces and its inactivation with biocidal agents. Journal of Hospital Infection. 
[18] Chen, H., Guo, J., Wang, C., Luo, F., Yu, X., Zhang, W., ... \& Liao, J. (2020). Clinical characteristics and intrauterine vertical transmission potential of COVID-19 infection in nine pregnant women: a retrospective review of medical records. The Lancet, 395(10226), 809-815.

[19] Chen, N., Zhou, M., Dong, X., Qu, J., Gong, F., Han, Y., ... \& Yu, T. (2020). Epidemiological and clinical characteristics of 99 cases of 2019 novel coronavirus pneumonia in Wuhan, China: a descriptive study. The Lancet, 395(10223), 507-513.

[20] Xu, X. W., Wu, X. X., Jiang, X. G., Xu, K. J., Ying, L. J., Ma, C. L., ... \& Sheng, J. F. (2020). Clinical findings in a group of patients infected with the 2019 novel coronavirus (SARS-Cov-2) outside of Wuhan, China: retrospective case series. $b m j, 368$.

[21] Chen, F., Liu, Z., Zhang, F. R., Xiong, R. H., Chen, Y., Cheng, X. F., ... \& Ren, J. (2020). Frist case of severe childhood novel coronavirus pneumonia in China. Zhonghua er ke za zhi= Chinese journal of pediatrics, 58, E005.

[22] Zeng, L. K., Tao, X. W., Yuan, W. H., Wang, J., Liu, X., \& Liu, Z. S. (2020). First case of neonate infected with novel coronavirus pneumonia in China. Zhonghua er ke za $z$ hi $=$ Chinese journal of pediatrics, 58, E009.

[23] Guan, W. J., Ni, Z. Y., Hu, Y., Liang, W. H., Ou, C. Q., He, J. X., ... \& Du, B. (2020). Clinical characteristics of coronavirus disease 2019 in China. New England journal of medicine.

[24] Chang, D., Xu, H., Rebaza, A., Sharma, L., \& Cruz, C. S. D. (2020). Protecting health-care workers from subclinical coronavirus infection. The Lancet Respiratory Medicine, 8(3), e13.

\section{Acknowledgements}

The author appreciates all those who participated in the study and helped to facilitate the research process.

\section{Conflict of Interest}

The author declared no conflict of interest.

How to cite this article: Kapatel. P, Nagma. M (2020). Probable immersions for novel Coronavirus and its preventions: A systematic review. International Journal of Indian Psychology, 8(2), 32-42. DIP:18.01.203/20200802, DOI:10.25215/0802.203 